Meta

Journal des traducteurs

Translators' Journal

\title{
Language Services at the Olympic Games
}

\section{Günther Beyer}

Volume 17, numéro 3, septembre 1972

URI : https://id.erudit.org/iderudit/002071ar

DOI : https://doi.org/10.7202/002071ar

Aller au sommaire du numéro

Éditeur(s)

Les Presses de l'Université de Montréal

ISSN

0026-0452 (imprimé)

1492-1421 (numérique)

Découvrir la revue

Citer cet article

Beyer, G. (1972). Language Services at the Olympic Games. Meta, 17(3), 143-151.

https://doi.org/10.7202/002071ar d'utilisation que vous pouvez consulter en ligne.

https://apropos.erudit.org/fr/usagers/politique-dutilisation/ 


\section{language services}

\section{at}

the 1972

\section{olympic}

\section{games}

A variety of specialized fields in linguistics have been described in the professional journals of recent years. Yet, no one has attempted to outline the professional profile of an individual whom, for want of a more modest designation, we shall call the head of language services. It appears worthwhile to describe his field since an understanding of the problems and motivations of this specialty will become increasingly significant to linguists as more and more national and supranational organizations and private companies acquire language services of their own.

These are the men and women who «sell $\gg$ the product of their colleagues to a user, providing a service not only to the employers of a foreign language department but also to their colleagues, the practising linguists whose interests they represent. With very few exceptions, practical experience as an interpreter, translator, or language teacher (preferably all three) is part of their professional background without which they cannot function effectively. The foreign language services which have been organized for the 1972 Olympic Games in Munich might yield a case history for the discussion of this field, since they can be used for an example to demonstrate all the "do's and don'ts》 of the profession. Moreover, since we do not yet have the benefit of hindsight as this article is being written, here is a wonderful chance for the language community to prove a «language functionary» wrong.

\section{BASIC CONSIDERATIONS}

The organizers of the 1972 Olympic Games wished to improve on previous Games where it was felt that the athletes competed but did not communicate adequately. It was their opinion that, by lowering the language barrier, they could accomplish a very worthwhile objective at relatively low cost. Consequently, there will be an impressive display of professional linguists and polyglots in Munich this year : 90 simultaneous interpreters, 270 additional interpreters and 
translators, 1500 hostesses speaking two foreign languages each. About five million words of printed literature will be published in German, English, French, Spanish and Russian, and some publications have been printed in as many as 20 foreign languages. The organizers decided on this ambitious program without the benefit of any linguist's advice; if they had sought such advice they might never have undertaken it, for professional language services certainly don't come cheaply, as they were to find out soon.

Indeed, it is at this early stage in the existence of an organization that the services of a competent linguist are critical. Most of the incorrigible mistakes are made during the initial planning phase of an operation. The crucial aspect is that the users wish to accomplish too ambitious a program with limited funds. They tend to underestimate the cost of translation, the personnel and time required to produce printed literature in foreign languages, the salaries which must be paid to professional interpreters. Thus, the linguist's first and most unpleasant task is to reconcile program and funds. If he cannot obtain the commitment of the necessary funds, or cut back the program to meet the available funding level, he had better refuse the job from the outset. It is at this point that his most important function begins, the never-ending task of « educating » the user. Patient explanation of linguistic requirements and, where necessary, tough negotiation for adequate conditions and funds, are called for. The following are two prerequisites that must be satisfied before a linguist can agree to undertake such an assignment : 1) Adequate budget to meet the contemplated program ;2) Absolute control of any linguistic aspect of the operation, including any intended employment of linguistic personnel by any department other than his own.

While the first requirement is self-explanatory, the second deserves some discussion. In an organization which maintains international relations there is hardly any activity that does not have some language aspects. Unless these are under single control, endless trouble will result. The Organizing Committee for the 1972 Olympic Games (where this requirement was not satisfied) provides innumerable examples of how not to do it. Translators and interpreters must be employed exclusively in the foreign language department of an organization. If the operating departments are allowed to hire their own translating staff it will become impossible to maintain quality standards and, moreover, the practice is very wasteful. It has never been possible to provide a continuous workload for translators working in a decentralized environment. Only their consolidation into a central activity serving all the users within an organization will allow the economical employment of these highly skilled and expensive specialists. Of course, under such an arrangement there must be priorities in times of peak workloads, and this means that some users will not be served as rapidly as they feel they should be. Consequently, they like to hire their own language staff. If this is permitted, the head of language services will be in continuous trouble and, unless he can defeat such attempts he might as well quit his job because it will become impossible to maintain quality control of the foreign-language texts produced within the organization. A poor alternative is that certain products of such decentralized language staff (for instance, any printed matter) be sub- 
mitted to him for approval, but experience has shown that such regulations are too frequently disregarded under the pressure of time. Once these poor products have appeared in print it won't help him to point out that he had nothing to do with their publication. He will be condemned by association. Of course, if he is to enforce such a control he must take care to serve the operating departments within a reasonable (and sometimes unreasonable) time frame, and this in turn means that he may have to exert pressure on his translators who may feel that the rush is unjustified.

Control of linguistic aspects involves many areas that are only indirectly concerned with translation. The linguist should not wait until he is consulted on such aspects by the users who, more often than not, tend to forget that language will have an impact on their projects. One example of this type will become evident to the public at the 1972 Olympics. People will find their way about the Olympic sites with the aid of trilingual signs on which the French (and sometimes even the English) will be abbreviated in the strangest ways. The reason for this is that the sign blanks (which have a very long lead time) were ordered to fit the German inscriptions; nobody thought at the time that the French or English equivalents might not fit into the available sign length. The linguists were not consulted until it became time to paint the signs, and by then it was too late. Actually, in an international program there is hardly any area without language implications; it is up to the linguist to see that he is consulted on these, and he must offer unsolicited advice, too. That the users failed to consult him will not excuse him when trouble results.

\section{ADVANCE PLANNING}

This author became involved in Olympic preparations at a rather late stage : 10 months before the Games. At that time the Organizing Committee had already existed for three years. Normally, a linguist should contribute to the very first and tentative planning for an international program. Here are some important areas where his advice can save the organizers money and trouble :

- Definition of the scope of linguistic efforts which will be required;

- Reconciliation of program and available funds (in simple words : each foreign language to be offered will cost so much money; if the funds are not available, the number of languages must be reduced) ;

- Establishing meaningful production schedules for multilingual publications (most producers tend to underestimate the time required to produce printed matter in a foreign language ; the correction of proof sheets alone may defeat an unrealistic production schedule) ;

- Establishing an organizational structure for an effective foreign language department ;

- Establishing the procedures to be observed by the operating departments in all matters affected by foreign languages.

It is during this early phase that the linguist himself will decide the success or failure of his developing language program. If he can convince the other 
planners of his competence, if he can show them that it will pay to consult him, he will be able to manage his part of the program without the interference which will otherwise become his most vexing problem.

Once the initial planning has been completed the next task will be to recruit an effective staff. As a rule, conference interpreters are the first specialty required when an international program takes shape ; a translating staff comes later, when an organization is in existence. In the case of the Olympic Organizing Committee this order was reversed : during the preparatory phase the operation required primarily translating services, especially to handle the enormous volume of foreignlanguage publications. Interpreters will not be needed until just prior to the Games.

\section{TRANSLATING STAFF}

The organization of an effective foreign language department begins with the recruitment of editors who must be native speakers of their respective target language. An editor (or revisor) is an experienced translator who can edit other translators' materials to produce manuscripts that are fit to print. It is readily seen that these are the key personnel of a foreign language department whose reputation in the respective language will be based on their professional competence. The editor must be recruited first, and he should be allowed a large voice in the recruitment of his translators, usually employed at a ratio of three to four per editor.

Translating to produce printed matter is teamwork. This should be an undisputable point, and yet it is difficult to convince users of its necessity. For instance, advertising men would not dream of printing a copywriter's product without extensive review and consultation; yet they will take any translator's product and have it printed without even looking at it. When they are told that the product is poor they will look for a better translator and will suffer the same disappointment all over, until they lose all confidence in the translating profession, whereas they need merely duplicate the production process used for the original text in order to obtain an acceptable translation : get another translator to revise the product of the first, and if it is an important publication, get a third, and make them agree on the final version.

Here are some of the significant aspects of producing good translations of printed matter :

- Employ native speakers of the target language exclusively; anyone who has lived outside his native country for more than five to eight years is no longer a native speaker in the sense of being able to produce authentic language that is fit to print ;

- Employ a native editor for every target language needed; where it is a rarely required language a free-lance editor may be acceptable to revise the work of a free-lance translator, but this is a poor second choice. If outside contracting is necessary because the translating volume does not merit an in-house translator or because the workload is too heavy for the regular staff to handle, at least the editing must be done in-house ; 
- Test your prospective native translators for proficiency in the source language, and have the finished translation product checked by a source language native to guard against misinterpretation of the source text. Provide native informants of the source language for consultation during the translating process;

- See that the editors produce by consensus with their translators, rather than by dictatorial methods. Teamwork implies the voluntary contributions of all the team members.

An organization of this type cannot only produce better quality than the free-lance translator working without assistance; it also produces it at a much lower cost even when the translators are paid a generous salary, provided that the workload ensures their reasonably continuous employment. This cost advantage has been demonstrated again and again in different types of organizations.

The foregoing is not intended to imply that the Organizing Committee for the 1972 Olympics has accomplished all of these objectives, especially not during the early phases of its existence where a considerable amount of foreign-language printed matter was produced which met with disapproval abroad. It was these misfortunes which finally convinced the Organizing Committee that outside contracting was the wrong approach and that an effective in-house capability had to be created, even at that rather late phase of preparations. But at the time of writing, three months before the Games, a language staff of seventeen professionals and three typists handles a weekly workload of about 300000 words of translation into five foreign languages at about one half the cost previously required for out-of-house contracting. This is accomplished in addition to the effort involved in organizing the interpreting services for the Games, screening the applications of some 2000 interpreters, testing the best prospects among these applicants, and training the accepted candidates.

\section{INTERPRETING SERVICES}

Interpreting is one of the most widely misunderstood professions in the world. The fact that interpreters are called «translators» in most Englishspeaking countries proves this. Interpreting is not primarily a matter of proficiency in foreign languages but an achievement in concentration and memory that is unique among the linguistic professions and, in fact, little research has been accomplished to date on its basic aspects. Here again, it is the task of the interpreter to «educate» his users. In an environment where most educated persons can more or less «speak» at least one foreign language and converse readily at cocktail parties, it is very difficult indeed to convince a layman that here is another linguistic task which requires a highly paid specialist. In this author's experience, the idea that anyone who can speak a foreign language «fluently » will also be able to serve as an interpreter, is one of the most difficult misconceptions to overcome.

The Organizing Committee plans to saturate the Olympic Village and the competition sites with polyglots of every conceivable type : hosts to assist the foreign delegations, hostesses speaking two foreign languages placed in strategic locations, trilingual announcers in the stadia, personnel with language proficiency 
placed wherever contact with the public results, etc., in addition to teams of professional interpreters employed for simultaneous interpretation at conferences, consecutive interpreting wherever difficult subject matter must be negotiated, press conferences, interviews for T.V., radio and the press, and the like. With such a proliferation it is almost impossible to induce planners to distinguish between professional interpreters and polyglots ; to some, all of these personnel are "interpreters», and will remain so until the Games are all over.

Again, program and funding must be reconciled in the early planning stage. A realistic assessment of the interpreting requirement versus the needs for polyglot personnel must be made and defended in the struggle for the available funds. This is most easily accomplished in the case of multilingual conferences (several congresses are scheduled to run concurrently with the Games) where simultaneous interpretation is planned. The cost of leasing the electronic equipment is readily determined, and the conference interpreters will not work at rates less than those prescribed by their professional association, the A.I.I.C. Thus it becomes merely a matter of explaining the cost to the organizers, waiting until they have stopped screaming, and patiently suggesting that their conference might succeed even if they dropped one or two foreign languages from their program.

The task is less simple for the remaining interpreters and polyglot personnel. Some of the initial euphoria was dampened when the hard realities of funding had to be allowed for. Thus, the initial plans for 5000 hostesses and some 500 interpreters were reduced to 1500 and 270 , respectively, and in order to meet the latter figure the German Government agreed to furnish about one half of them from its inventory of permanent government employees so that the Organizing Committee only had to recruit the remaining 135 interpreters. The 135 government employees will be organized and controlled by the Federal Bureau of Languages in Hürth (a suburb of Cologne) and will work primarily in the competition sites. They started training for their respective sports disciplines more than a year before the Games.

Systems analysis to acquire quantified data for planning these interpreting services proved difficult because this will be the first time that professional interpreting plays a major role at Olympic Games, while polyglot hostess services have been offered more frequently. The few empirical data reported from previous Games suffer from the lack of a distinction between polyglots and professional linguists so that they do not provide a meaningful statement. However, since the level of services was already decided arbitrarily by the available funding, it appeared adequate to obtain some qualitative data, i.e., to decide on an optimum ratio between the languages represented in this staff of interpreters so that the arising demand might be met with a minimum of shortages and overages.

The official languages recognized at the Olympic Games will be French and English plus the language of the host nation, German. In addition, the International Olympic Committee (I.O.C.) decided some time ago that Spanish and Russian were to be accorded equal standing. This means that any official function must make allowance for these five languages which we call the «Olympic Languages ». Secondary indicators for the language structure of our body of 
interpreters are the population structure in the Olympic Village and the native languages of medal winners at previous Games (significant for T.V., radio, press interviews and the like). These statistics provide some interesting data.

Importance of the native languages of the Olympic Village population (athletes and their officials) in 1972 :
1. English
2. Spanish
2500
6. Polish
480
3. French
7. Arabic
470
4. German
8. Italian
430
5. Russian
9. Korean
380
600 10. Hungarian 360

The significance accorded the Olympic Games by the socialist nations becomes evident from these data.

The ten most frequent native languages of Olympic medal winners, 18961964 :
1. English
2. German
3. French
4. Russian
5. Swedish

1998

584

383

6. Finnish

243

7. Hungarian 230

8. Italian 199

9. Japanese

199

10. Dutch

120

The shift in emphasis appears striking. Spanish, occupying second place in the Olympic Village population, holds only 12th place among the medal winners, while Arabic (18 medals) is last among the medal winners.

Accordingly, the «Olympic languages » English, French, Spanish, Russian and German will be most frequent among the Olympic interpreters, followed by languages such as Italian, Japanese, Portuguese, Arabic and the languages of the large delegations from socialist nations, while the remainder of the approximately 30 languages represented will be covered by only one interpreter each, usually in combination with some other foreign language.

\section{RECRUITING INTERPRETERS}

The Organizing Committee received about 2000 unsolicited applications from persons all over the world who felt qualified as interpreters. However, only a small percentage of these merited consideration, the majority being polyglots qualified for a variety of jobs at the Games, but not for professional interpreting. In spite of the unattractive financial conditions - while the simultaneous interpreters will receive their customary remuneration, ad hoc interpreters will have room, board and pocket money only - there has been a gratifying interest in these 135 jobs, motivated primarily by a desire to be on the scene and part of the international community at the Games.

The two primary criteria for the selection of applicants were 1) professional training as an interpreter and 2) residence in the country of the first foreign language claimed. Applicants who met these requirements were called in for a test, regardless of the grades obtained upon graduation from their interpreting school. That this procedure was justified is proven by the fact that, in spite of 
the most careful screening of applications, only one out of three applicants was able to pass the test. This is not a novel experience to employers of interpreters in Europe. The grades vary considerably even between the different language departments of one and the same school, and in most schools a poor grade in translating or interpreting classes can be offset by a good thesis so that it is really difficult for a prospective employer to judge an applicant's qualification from the grades listed on his college diploma. As a result, it has become the accepted practice of major language services in Europe to hold entrance examinations for job applicants.

The selection of test criteria had to be a compromise between that which was desirable and that which could be accomplished in the limited time available to applicants as well as examiners, since the latter had regular duties as foreignlanguage editors. Consequently, each applicant was required to produce a written translation of two short texts (about 250 words) from and into his best foreign language. Since this translation had to be prepared without any dictionary whatever, it provided a good indication of the candidate's active vocabulary in the foreign language concerned, in addition to his or her facility in managing the transposition of ideas from one language into another.

The oral test had to be confined to a determination of speaking proficiency in the languages claimed, in addition to detecting the characteristic traits of an interpreter : a forceful, outgoing personality, broad spectrum of interests, ability to «think on one's feet », not letting oneself be intimidated, not becoming rattled by unexpected situations. It would have been extremely desirable to have actual interpreting tests, but these would have required too much time. Even so, it is possible that the rather long procession of young jobseeking introverts who failed these tests bear a real grudge against us; however, interpreting is a rough game where only the fittest can survive. It is possible that we refused a good prospect occasionally; after all, this is a negative selection technique. But there will be few failures among the 135 persons accepted out of the 400 tested applicants. Care was taken to have a ratio of approximately $50 \%$ between native speakers of the German language and of the foreign languages concerned, so this will be a truly international club of interpreters, in keeping with the spirit of the Olympic Games.

\section{INTERPRETER TRAINING}

Interpreters have learned in their professional schools that thorough familiarization with the potential subject matter of an assignment is half the success. Consequently, we have planned a familiarization program that will make it easier for the interpreters to do their job at the Games. Starting about three months prior to the opening ceremony they will receive regular shipments of literature on the Olympic Games in the different languages concerned, reinforced by a programmed instruction course in the 21 Olympic sports disciplines and a programmed familiarization course on the Olympic facilities in Munich. Finally, the interpreters will arrive at an early time (four weeks prior to the Games), and this familiarization period will be filled up with tours of the grounds, on-the-job training (primar- 
ily in the form of translating work, the best method of acquiring a new vocabulary), lectures, and the like. This program will be handled in a very flexible manner, and there will be a smooth transition to actual interpreting assignments which are expected to increase gradually between August 1 and the opening ceremony.

\section{CONCLUSION}

While the situation prevailing in Munich is unique in many ways, the basic tenets of organizing a foreign language service remain more or less the same, regardless of the type of user. This author has encountered or practised them in government agencies and supranational organizations on both sides of the Atlantic, and in large, export-oriented companies. They remain the same regardless of whether the subject is sports or military science, engineering or the natural sciences, economics or international law. Certainly, a short-lived assignment such as the preparation of the Olympic Games requires that the art of improvising problem solutions be developed to a greater degree than in organizations of a more permanent nature. It is said that Germans tend to over-organize because they can't improvise. However, an improvised operation which is not backed up by a staff with the required talent will be nothing better than an amateurish effort. We in Munich have tried to attract that talent.

GÜNTHER BEYER 